\title{
A Review of Sustainable Supply Chain Management Based on Game Theory
}

\author{
Ying Zhou ${ }^{1}$ and Fan Qin ${ }^{2, *}$ \\ ${ }^{1}$ Sino-US Global Logistics Institute, Shanghai Jiao Tong University, Shanghai, China \\ ${ }^{2}$ Business School, Nankai University, Tianjin, China \\ ${ }^{*}$ Corresponding author
}

\begin{abstract}
More and more attention has been paid to the sustainable supply chain management (SSCM) by scholars and practitioners since it concerns about both the social and environmental benefits of supply chain. Meanwhile, game analysis has proven to be an effective research method in SSCM research. This research reviews related domestic and foreign literature published in famous academic journals from 2001 to 2013 via applying content analysis method which is based on three analysis dimensions (performance objective, game element and coordination mechanism). By analyzing existing related papers on each dimension respectively, it is concluded that only few papers concerned about social benefit, demand uncertainty and information asymmetry. Considering these three dimensions synthetically, it can be summarized that a large proportion of researchers did not go deep enough into the study of complicated supply network and coordination in the field of SSCM based on the game theory. This review illustrates the current research situation and makes some suggestions for future further researches.
\end{abstract}

Keywords-sustainable supply chain; game theory; content analysis; supply chain contract

\section{INTRODUCTION}

With the development of economy and the society, environmental protection and social responsibility have been paid more attention. Meanwhile, supply chain management's focus has been transferred from economic issues to environmental and social issues. Reverse logistics was derived from traditional supply chain, because of internal and external reasons, such as regulations promulgated by the government, environmental issues, more attention paid to improving customer satisfaction, increasing product recalling rate and disposal rate. Afterwards, Manufacturing Research Association in Michigan State University first introduced the definition of green supply chain in 1996. Following, closed-loop supply chain management theory structure was developed based on the combination of reverse logistics and traditional supply chain. In the 21th century, the concept of sustainability has become relatively complete since it was first put forward by Brundtland Commission in 1987. Economic, environmental and social responsibilities are commonly recognized as Triple Bottom Line of organizational sustainability. The concept of sustainable supply chain management (SSCM) established based on it.

Seuring et al. [1] have defined SSCM as the management of material, information and capital flows as well as cooperation among companies along the supply chain while taking goals from all three dimensions of sustainable development, i.e., economic, environmental and social, into account which are derived from customer and stakeholder requirements. So far, some researchers have reviewed on the SSCM from different views. Seuring et al. [2] have reviewed related papers in different levels which can be divided into descriptive and analytical categories. Descriptive category includes time-independent distribution of literature from 1994 to 2004, major journals' degree of concern for the theme and research methods on the theme used in major journals. Analytical category includes the dimensions of coverage of sustainable development, the relationship between business goals and sustainable development goals. Then Seuring S[3] has analyzed 36 related papers from 1997 to 2010 and summarizes research on quantitative models for forward green or sustainable supply chains. He has discussed the research status from the side of performance objectives (mainly including social and environmental side), and research method (including modeling research and empirical research) comprehensively.

Game theory is a widely-used research method in the field of supply chain since it's an effective decision tool to solve interactive decision-making problems in supply chain. Among all the researches on the supply chain based on the game theory, Zhang et al. [4] have reviewed supply chain contract research during 2003 to 2011 from the side of research theme, problem dimensions and method type. The paper concludes that the game theory has become more and more popular in the supply chain coordination research; Li et al.[5] have analyzed papers in management filed whose theme is profit distribution in the supply chain, which published in 30 authoritative journals from 2000 to 2009. The paper analyzes the research status from the sides of five game factors and concludes that contracting is a common method to distribute profit and increase the entire supply chain profit.

Although the game theory has been applied comprehensively in supply chain management research, there are relatively less researches focusing on sustainable supply chain based on game analysis. Thus this paper focuses on this theme, sorts out related papers, concludes the research status and suggests future research.

\section{THE METHOD FOR LITERATURE REVIEW}

Content analysis is an effective research method to analyze papers objectively, systematically and quantitatively. For its objectivity and repeatability, it is applied in different research fields widely. Given past research achievements when using content analysis in literature review, this paper applies this method. 


\section{A. Journal Selection}

For selecting the related papers, we have chosen 30 Chinese journals which are designated by the National Natural Science Foundation of China, 29 English management journals whose impact factor are higher than 1.3 and some journals in related research area whose impact factor is higher than 2. Thus 38 related Chinese papers and 17 English papers were identified by means of a structured key word research on major databases and publisher and publisher websites (CNKI database, Elsevier ScienceDirect, Wiley interscience, ISI Web of Knowledge, Springlink, et al.) The key words used for searching include "closed-loop supply chain”, "green supply chain", "sustainable", "game theory". In order to keep the result reliable, all the papers were checked more than once.

TABLE I. CLASSIFICATION CATEGORIES AND CODES

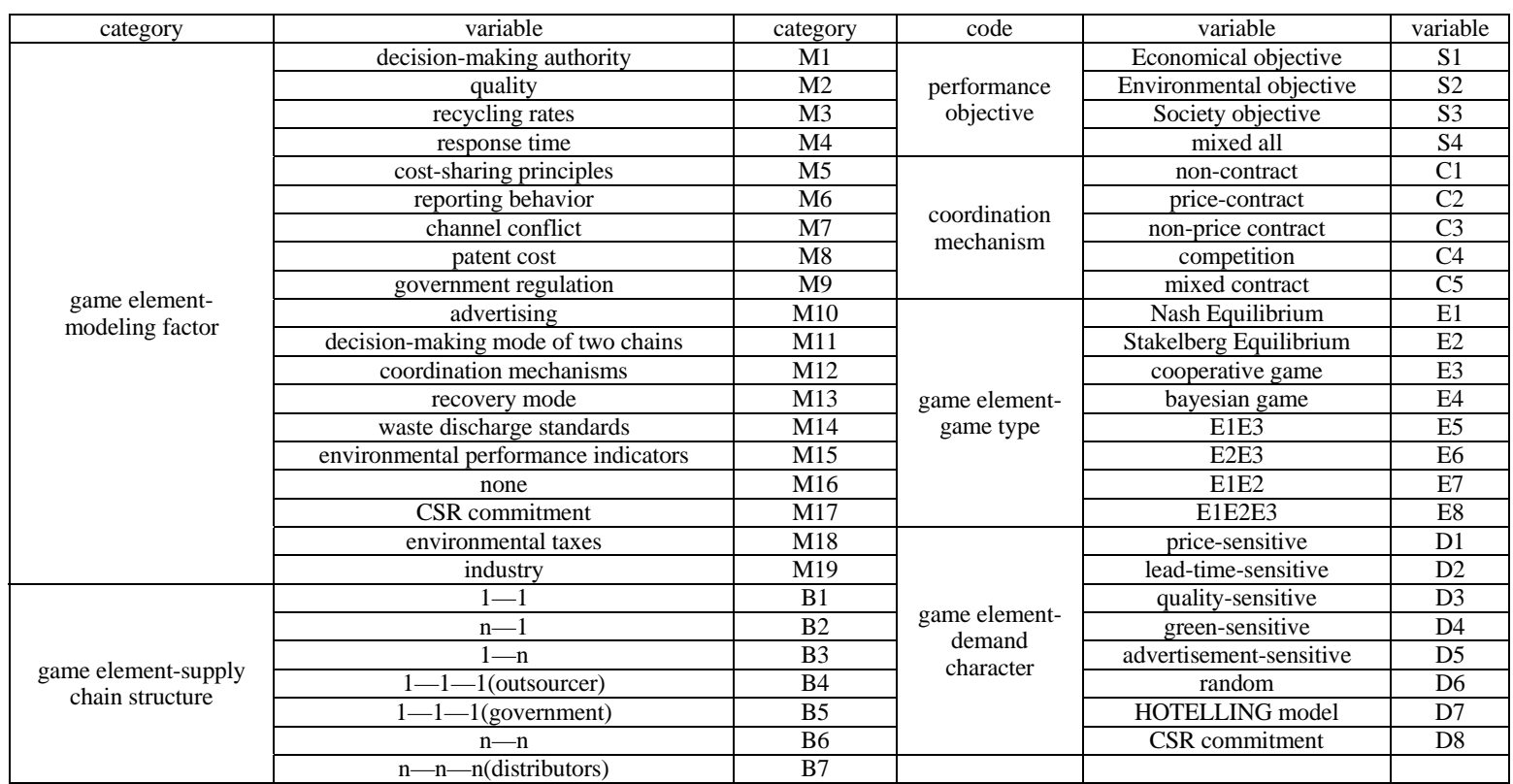

\section{B. Analysis Items}

Establishing analysis items and coding them are key processes in content analysis. Considering the purpose of this research is to explore more future research questions in game analysis of SSCM, the analysis items are established as performance objectives, game element and coordination mechanism (see Table 1).

\section{1) Performance objectives}

Performance objectives of SSCM often include economical, environmental and social objective. Economical objective is a traditional and basic objective of SSCM, which is connected closely with finance. Environmental objective is related to ecology protection and resource saving. Social objective reflects the relationship between the corporate and the society, which contributes to social harmony.

\section{2) Game elements}

In a game model, some game elements, such as players, game rules, parameter's type et al., determined the model's simulation ability and model's solvability. Players involved in supply chain game influence the complexity of supply chain. As we know, forecast cannot keep up with demand due to fierce competition and shorter product life span. Therefore it is more practical to consider demand character during game theory analysis. Game rule and controlling parameter reflect decision process and model's simulation ability respectively. Thus, four key game elements, demand character, supply chain structure which determined by the players involved in a considered supply chain, game rule and parameter's type, are applied for literature analysis.

\section{3) Game coordination}

It is indispensable for supply chain members to employ effective coordination mechanism to lessen or even avoid operational conflict from each other. In this way, though they do not have the same operational target completely, they have to work together to realize the whole goal of the sustainable supply chain even only considering their own benefits. Contract is one of the most common types of coordination mechanism. Many researches inclined to coordinate supply chain by adjusting price. But some other researchers proposed to integrate supply chain by adjusting other operational factors. Thus, all coordination mechanisms can be divided into two types, i.e. price contract coordination and non-price contract coordination. In some cases, one contract adjusts price and other factors simultaneously so as to solve the supply chain problem more effectively.

\section{LITERATURE ANALYSIS}

\section{A. Performance Objectives Analysis}

\section{1) Economical objective}

All the collected papers discussed the economical objective. Overall, papers which only take the economic dimension into consideration account for almost $70.91 \%$ of all the collected papers. In some other researches, closed-loop supply chain research is taken as the samples which require environmental 
objective. However, some papers mainly focus their research on product recovery value. Obviously, these researches consider little of environmental benefit and they can only be taken as samples which only consider economical objective.

\section{2) Economical and environmental objectives}

There are only 3 Chinese papers considering environmental objectives in all selected papers. Li et al.[6] analyze green production. Furthermore, supply chain efficiency and levels of effort of supplier and manufacturer are compared in two different market structures. Zhu et al.[7] considers green degree of product in a three-stage game theory analysis. Green degree of product is a metric closely relate to the environmental objective. Jin et al.[8] analyze the choice of green marketing strategy between two retailers and conclude that the more consumers prefer green products, the more retailers will choose green marketing strategy when the government offers the enough subsidy. Only in this situation will environmental benefit be better. Environmental benefit-oriented researches presented in English papers occur earlier than in Chinese papers. The number of related English papers is three times more than Chinese ones (see Table 2).

TABLE II. THE NUMBER OF CHINESE AND ENGLISH PAPERS FOCUSING ON DIFFERENT PERFORMANCE OBJECTIVES

\begin{tabular}{|c|c|c|c|c|}
\hline & S1 & S2 & S3 & S4 \\
\hline Num of Chinese papers & 35 & 3 & 0 & 0 \\
\hline Num of English papers & 4 & 12 & 1 & 0 \\
\hline Proportion & $70.9 \%$ & $27.3 \%$ & $1.8 \%$ & $0.0 \%$ \\
\hline
\end{tabular}

\section{3) Economical and social objectives}

Few papers take social objective into account among all the related Chinese papers. While some Chinese papers are not included in our research since they are not related to the game theory, these papers have discussed corporation social responsibility in SSCM. Especially, several researchers take social objective as a special kind of environmental objective. Cruz et al. [9-11, 12] confuses the two kinds of performance objective and take the environmental objective into the corporate social responsibility objective. Nagurney et al. [13] discuss the promise of corporate social responsibility and the corporate that makes the promise will produce the better product for consumers aiming at the three types of performance objective simultaneously. This is the only paper to discuss the social objective among all selected papers. Table 2 provides the number of Chinese and English papers focusing on different performance objectives.

\section{B. Game Elements Analysis}

\section{1) Supply chain structure}

TABLE III. SUPPLY CHAIN STRUCTURE PRESENTED IN CHINESE AND ENGLISH PAPERS

\begin{tabular}{|c|c|c|c|}
\hline & Chinese papers & English papers & total \\
\hline B1 & 21 & 6 & $49.1 \%$ \\
\hline B2 & 1 & 0 & $1.8 \%$ \\
\hline B3 & 2 & 1 & $5.5 \%$ \\
\hline B4 & 9 & 4 & $23.6 \%$ \\
\hline B5 & 5 & 1 & $10.9 \%$ \\
\hline B6 & 0 & 4 & $7.3 \%$ \\
\hline B7 & 0 & 1 & $1.8 \%$ \\
\hline total & 38 & 17 & $100.0 \%$ \\
\hline
\end{tabular}

There are 7 types of supply chain structure presented in Chinese and English papers (see table 1). By classifying all selected papers, it can be found that nearly half of the papers are discussing two-stage supply chain. A quarter of the papers consider outsourcers in the three-stage supply chain, and the effect of government on the three-stage SSCM is analyzed in $10.91 \%$ of related papers. Comparing Chinese papers and English papers, it can be concluded that Chinese researches more often stay in the chain structure of supply chain instead of network one. Otherwise, some articles discuss the situation that there are more than one player in one stage. For example, Yi and Zhang et al. [14,15] analyze a supply chain which is made up of one manufacturer and several retainers; Han [16] consider one retainer and several manufacturers in turn. On the other hand, supply chain network structure is more complex in English papers in which Hsueh [12] discusses a complex three-stage model considering distributor. Table 3 describes the numbers of different kinds of supply chain structure presented in related Chinese and English papers.

TABLE IV. DEMAND CHARACTER ANALYSIS

\begin{tabular}{|c|c|c|c|c|}
\hline & D1 & D2 & D3 & D4 \\
\hline quantity & 38 & 1 & 1 & 10 \\
\hline proportion & $69.1 \%$ & $1.8 \%$ & $1.8 \%$ & $18.2 \%$ \\
\hline & $\mathrm{D} 5$ & $\mathrm{D} 6$ & $\mathrm{D} 7$ & $\mathrm{D} 8$ \\
\hline quantity & 3 & 0 & 1 & 1 \\
\hline proportion & $5.5 \%$ & $0.0 \%$ & $1.8 \%$ & $1.8 \%$ \\
\hline
\end{tabular}

\section{2) Demand character}

Market demand character is often classified into three categories, namely price-sensitive, non-price-sensitive and random demand. As a result, 69.1\% of the papers establish model based on price-sensitive demand (see table 4).

\section{3) Game type}

Nash equilibrium and Stackelberg equilibrium in non-cooperative game, cooperative game and Bayesian game are four common types of game analysis model in the supply chain management. Except for Bayesian game, other types of game model are all discussed in collected papers. Table 5 describes the game type in all papers.

\section{TABLE V. GAME TYPE ANALYSIS}

\begin{tabular}{|c|c|c|c|c|}
\hline & E1 & E2 & E3 & E4 \\
\hline quantity & 7 & 12 & 7 & 0 \\
\hline proportion & $12.7 \%$ & $21.8 \%$ & $12.7 \%$ & $0.0 \%$ \\
\hline & $\mathrm{E} 5$ & $\mathrm{E} 6$ & $\mathrm{E} 7$ & $\mathrm{E} 8$ \\
\hline quantity & 4 & 17 & 3 & 5 \\
\hline proportion & $7.3 \%$ & $30.9 \%$ & $5.5 \%$ & $9.1 \%$ \\
\hline
\end{tabular}

4) Modeling factor

After analyzing all the collected papers, we can find 18 modeling factors (see table 1). More than 5 papers discuss government regulation, decision-making authority, coordination mechanisms and channel conflict respectively. In the early development of supply chain, it is necessary to form governmental encouragement and supervision when coordination mechanisms are not complete. Decision-making authority and channel conflict are often mentioned when researching the complicated supply chain structure. Table 6 describes the usage of modeling factors in all the related papers. 
TABLE VI. USAGE OF MODELING FACTORS

\begin{tabular}{|c|c|c|c|c|c|c|}
\hline M1 & M2 & M3 & M4 & M5 & M6 & M7 \\
\hline 7 & 3 & 1 & 1 & 1 & 1 & 6 \\
\hline M8 & M9 & M10 & M11 & M12 & M13 & M14 \\
\hline 2 & 6 & 2 & 1 & 11 & 3 & 4 \\
\hline M15 & M16 & M17 & M18 & M19 & & \\
\hline 1 & 1 & 1 & 1 & 2 & & \\
\hline
\end{tabular}

\section{Coordination Mechanism Analysis}

There are two types of relationship among game players of supply chain. One is competition, the other is cooperation. If players choose cooperation, they can coordinate the supply chain through contract or non-contract coordination. Table 7 describes the condition of coordination mechanism in all the collected papers.

\section{TABLE VII. COORDINATION MECHANISM ANALYSIS}

\begin{tabular}{|c|c|c|c|c|c|}
\hline & C1 & C2 & C3 & C4 & C5 \\
\hline quantity & 3 & 18 & 10 & 20 & 4 \\
\hline proportion & $5.5 \%$ & $32.7 \%$ & $18.2 \%$ & $36.4 \%$ & $7.3 \%$ \\
\hline
\end{tabular}

\section{1) Non-contract coordination}

Non-contract coordination is to cooperate through other methods instead of contract. Though Wang et al. [17, 18] discusses non-contract coordination and indicates that cooperation brings more benefit. Their research concludes that non-contract coordination is not stable and contract is necessary to regulate supply chain members' behavior. These two papers appeared in the early stage of SSCM on game theory. Afterwards, almost all the papers discussed contract coordination when talking about cooperation. However, Wei et al.[19] combine fuzzy theory and game theory so as to get the best price without the contract coordination.

\section{2) Contract coordination}

Contract coordination is to cooperate through contract. Price-contract and non-price-contract are two types of contract coordination. As table 7 has showed, quantity of price-contract papers (C2) are more than that of non-price-contract papers (C3). What's more, mixed coordination combining price and non-price factors (C5) are used in 4 papers.

\section{3) Competition}

The majority of papers only consider the relationship of competition among players. $\mathrm{Ni}$ et al.[20] introduces the corporate social responsibility promise into the research and finally forms a win-win result without contract. The rest papers focus on the profit effect of modeling factors, such as the comparison of different authority structure, recycle channel et al.

\section{SYNTHETIC ANALYSIS}

Based on above discussion, as the three analysis items mentioned above are discussed synthetically, some meaningful conclusions could be made. A two dimension analysis is done in our research. One dimension is made up of performance objectives and supply chain structure, and the other one is coordination mechanism. Table 8 describes the result of synthetic analysis.
It can be concluded from table 8 that in the papers only considering economical objective, no papers research on three-stage supply chain structure which is made up of several retailers, several manufacturers and several distributors. Meanwhile, no papers go deep into the research of non-pricing coordination in these papers.

\section{TABLE VIII. TWO DIMENSION ANALYSIS}

\begin{tabular}{|c|c|c|c|c|c|c|c|}
\hline & & C1 & C2 & C3 & C4 & C5 & total \\
\hline & S1 & 3 & 14 & 7 & 12 & 3 & 39 \\
\hline (S1,B1) & B1 & 2 & 6 & 4 & 6 & 2 & 20 \\
\hline (S1,B2) & B2 & 0 & 0 & 0 & 1 & 0 & 1 \\
\hline (S1,B3) & B3 & 1 & 1 & 0 & 1 & 0 & 3 \\
\hline (S1,B4) & B4 & 0 & 7 & 3 & 1 & 1 & 12 \\
\hline (S1,B5) & B5 & 0 & 0 & 0 & 3 & 0 & 3 \\
\hline & S2 & 0 & 4 & 3 & 7 & 1 & 15 \\
\hline (S2,B1) & B1 & 0 & 3 & 1 & 1 & 1 & 6 \\
\hline (S2,B4) & B4 & 0 & 0 & 1 & 0 & 0 & 1 \\
\hline (S2,B5) & B5 & 0 & 0 & 0 & 3 & 0 & 3 \\
\hline (S2,B6) & B6 & 0 & 1 & 0 & 3 & 0 & 4 \\
\hline (S2,B7) & B7 & 0 & 0 & 1 & 0 & 0 & 1 \\
\hline & S3 & 0 & 0 & 0 & 1 & 0 & 1 \\
\hline (S3,B1) & B1 & 0 & 0 & 0 & 1 & 0 & 1 \\
\hline & total & 3 & 18 & 10 & 20 & 4 & 55 \\
\hline
\end{tabular}

Though there are not many papers focusing on environmental objective, these papers consider complicated supply chain network structure, cooperative game and non-pricing coordination. Furthermore, mixed coordination mechanism is used in one paper.

There are only one paper analyzes social objective of a two-stage supply chain which consist of one retainer and one manufacturer. It is still a long way to further study.

\section{CONCLUSION}

The paper provides a review of the statue of research on supply chain management based on game theory. The related 55 papers in the field are collected and analyzed which were published in main academic journals from 2001 to 2013. Content analysis method is used to categorize all collected papers based on three different analysis items (performance objective, game element and coordination mechanism). Based on above analysis, some conclusion can be made:

- Until now, most researches who study on supply chain coordination still only focus on economical objective of SSCM. Environmental benefit has been paid more and more attention. However, almost none papers about supply chain game coordination consider social benefit.

- In the Chinese papers, all researches still stay in the chain structure analysis instead of network one. Among all the papers only considering economical objective, no papers research on three-stage supply chain structure including several retailers, several manufacturers and several distributors. Papers discussing environmental benefit analyze more complicated supply chain network structure. The only one paper analyzing social objective just only analyzes a two-stage supply chain.

- There are not paper that consider the random demand.

- There are not information asymmetry research in all the related papers 
- Though there have been many modeling factors that are considered in collected papers, some other factors which will enhance the game model's simulation ability can be included within future research, such as new regulations promulgated, industry standards, e-commerce effect and so on.

- The related papers analyze some types of contract such as profit-sharing contract, volume discounts contract and franchise fees contract. Some other contracts are also available, such as number-flexible contract, price subsidy contract and mixed contract.

Based on the above analysis, some suggestions can be proposed for future research:

- Scholars need to balance economic benefit, environmental benefit and social benefit rather than focus on the economic benefit and ignore the others. It is a challenge to specify the social objective into research model.

- Scholars should analyze more complicated supply network so as to keep pace with supply chain development in reality. It may be more valuable to increase the quantity of stage in the supply chain and plus players in every stage.

- Random demand and information asymmetry are common conditions in the complicated supply chain. Thus researchers need to take them into consideration in the future research.

- Cost and profit sharing contract is used frequently in the current research. While every contract has its special benefit, it may make a difference and better result to combine several types of contract together in the future research.

\section{REFERENCES}

[1] Seuring S, Müller M. From a literature review to a conceptual framework for sustainable supply chain management [J]. Journal of cleaner production, 2008, 16(15): 1699-1710.

[2] Seuring S, Müller M, Westhaus M, et al. Conducting a Literature Review-the Example of Sustainability in Supply Chains [M]//Research methodologies in supply chain management. Physica-Verlag HD, 2005: 91-106.

[3] Seuring S. A review of modeling approaches for sustainable supply chain management [J]. Decision Support Systems, 2013, 54(4): 1513-1520.

[4] Zhang Hong, Yuan Qiong, Wang Ai-hu. Topic, Dimensions and Methodology of Supply Chain Contract Research- A Content Analysis Based on Academic Papers [J]. Industrial Engineering and Management, 2013, 18(3): 5-10.

[5] Li Han, Wang Li, Qian Wei. Review of Supply Chain Profit Distribution Research in China [J]. Science Technology and Engineering, 2010 (23): 5680-5687.

[6] Li Rui-hai, Zhang Tao . Reduction-manufacturing Efficiency Research of Green Supply Chain Based on Cooperative and Non-Cooperative Games[J]. Journal of Systems \& Management, 2009,04:432-435.

[7] Zhu Qing-hua, Dou Yi-jie. An Evolutionary Model Between Governments Core-Enterprises in Green Supply Chains [J]. Systems Engineering-Theory \& Practice,2007,12:85-89+95.

[8] Jin Chang-fei, Cao Er-bao, Lai Ming-yong . Analysis on Green Marketing Strategy of Duopoly Retailing Market Based on the Evolutionary Game Theory [J]. Journal of Systems Engineering, 2012, 03: 383-389.
[9] Cruz J M, Matsypura D. Supply Chain Networks with Corporate Social Responsibility Through Integrated Environmental Decision-making [J]. International Journal of Production Research, 2009, 47(3): 621-648.

[10] Cruz J M. Dynamics of Supply Chain Networks with Corporate Social Responsibility Through Integrated Environmental Decision-Making [J]. European Journal of Operational Research, 2008, 184(3): 1005-1031.

[11] Cruz J M. The Impact of Corporate Social Responsibility in Supply Chain Management: Multicriteria Decision-Making Approach [J]. Decision Support Systems, 2009, 48(1): 224-236.

[12] Hsueh C F, Chang M S. Equilibrium Analysis and Corporate Social Responsibility for Supply Chain Integration [J]. European Journal of Operational Research, 2008, 190(1): 116-129.

[13] Nagurney A, Yu M. Sustainable Fashion Supply Chain Management under Oligopolistic Competition and Brand Differentiation [J]. International Journal of Production Economics, 2012, 135(2): 532-540.

[14] Yi Yu-yin. The Competitive Retailer's Reproduction Closed-Loop Supply Chain Model Research [J]. Journal of Management Sciences in China, 2009, 06:45-54.

[15] Zhang Ke-yong, Zhou Guo-hua. Price Decision Analysis of Closed-Loop Supply Chain with Retailers Competition[J]. Operations Research and Management Science, 2008,06:44-49.

[16] Han Xiao-hua. Recycle Channel Decision Analysis of the Closed-loop Supply Chain Based on Manufacture's Competition [J]. Systems Engineering,2010,05:36-41.

[17] Wang Yu-yan, LI Bang-yi, Yue Fei-fei. The research on Two Price Decision Models of the Closed-Loop Supply Chain [J]. Forecasting, 2006,06:70-73.

[18] Wang Yu-yan. Study on the Delivery Response Time Decision Mode of MT-CLSC [J]. Operations Research and Management Science, 2009, 02:59-65.

[19] Wei J, Zhao J. Pricing Decisions with Retail Competition in a Fuzzy Closed-Loop Supply Chain [J]. Expert Systems with Applications, 2011, 38(9): 11209-11216.

[20] Ni D, Li K W. A Game-Theoretic Analysis of Social Responsibility Conduct in Two-Echelon Supply Chains[J]. International Journal of Production Economics, 2012, 138(2): 303-313. 